\title{
The role of fluorescence diagnosis in clinical practice
}

This article was published in the following Dove Press journal:

OncoTargets and Therapy

24 July 2013

Number of times this article has been viewed

\author{
Aleksander Sieroń \\ Karolina Sieroń-Stołtny' \\ Aleksandra Kawczyk- \\ Krupka' \\ Wojciech Latos' \\ Sebastian Kwiatek' \\ Dariusz Straszak' \\ Andrzej M Bugaj',2 \\ 'Clinical Department of Internal \\ Diseases, Angiology and Physical \\ Medicine, Center for Laser \\ Diagnostics and Therapy, Silesian \\ Medical University, Bytom, ${ }^{2}$ College \\ of Health, Beauty Care and Education, \\ Poznań, Poland
}

\begin{abstract}
Fluorescence diagnosis is a fast, easy, noninvasive, selective, and sensitive diagnostic tool for estimation of treatment results in oncology. In clinical practice the use of photodynamic diagnosis is focused on five targets: detection for prevention of malignant transformation precancerous changes, detection of neoplasmatic tissue in the early stages for fast removal, prevention of expansion and detection of recurrence of the cancer, monitoring therapy, and the possibility of excluding neoplasmatic disease. In this article, selected applications of fluorescence diagnosis at the Center for Laser Diagnostics and Therapy in Bytom, Poland, for each of these targets are presented.
\end{abstract}

Keywords: autofluorescence, cancer, fluorescence, imaging, photodynamic diagnosis, photodynamic therapy

\section{Introduction}

Fluorescence diagnosis is a fast and noninvasive method for imaging of precancerous and cancerous tissues in many locations. Many applications of this method have been discussed in the wide fields of oncology, dermatology, laryngology, pulmonology, gynecology, and gastroenterology. ${ }^{1-3}$ In many studies, this method has been described as very sensitive and specific especially in diagnostics of small changes that are not visible using white light endoscopic procedures. ${ }^{2-4}$

In endoscopic fluorescence diagnosis we can distinguish two major directions: ${ }^{5-10}$ (1) autofluorescence and exogenous (fluorophore-enhanced) fluorescence, depending on the origin of the fluorescent signal detected; and (2) point measurements and multidimensional imaging (tomography), depending on the signal detected.

\section{Autofluorescence diagnosis}

Autofluorescence is generated by endogenous molecules, such as aromatic amino acids, nicotinamide adenine dinucleotide, or porphyrins. ${ }^{10,11}$ This method has been described as very sensitive and specific especially in diagnosing small changes that are not visible using white light endoscopic procedures. ${ }^{6,11,12}$ Red fluorescence is stronger in the tumor tissue, in contrast to normal tissue, whose fluorescence is mainly green. As autofluorescence may be disturbed by false positive effects due to inflammation or neovascularization, many authors use the intensity ratios red-to-green, red-to-blue, or vice versa to evaluate neoplastic changes in the tissues. ${ }^{13,14}$ The red:green ratio is used as a basis of Xillix ${ }^{\circledR}$ Laser-Induced Fluorescence Endoscopy (LIFE) (Xillix Technologies Corporation, Richmond, BC, Canada) as a technique for detection of cancerous lesions. ${ }^{8,10}$ This system uses blue light excitation and can detect both green
Correspondence: Andrzej M Bugaj

Os Jagiellońskie $3 \mathrm{~m} 9$,

6I-224 Poznań, Poland

Tel +4850 l 645004

Email andrzej.marcin.bugaj@gmail.com which permits unrestricted noncommercial use, provided the original work is properly cited. 
and red tissue autofluorescence, applying band-pass filters before two image intensifier cameras for observation of native fluorescence in the green and red spectral ranges, which are fused to create a real time red-green image of the pathological changes. ${ }^{10,14}$ As a result of numerical analysis we can transform the autofluorescence image into a spatial map of Numerical Color Value (NCV) to establish the quality of imaging and to show places with the highest red:green ratio where the biopsy specimen was taken. ${ }^{15}$

\section{Exogenous fluorescence diagnosis}

Exogenous fluorescence diagnosis is based on the use of exogenous fluorophores revealing certain tumor selectivity, such as porphyrins, chlorins, phthalocyanines, or 5-aminolevulinic acid (ALA), a natural precursor of protoporphyrin IX which selectively accumulates in tumor tissues showing red fluorescence. ${ }^{10,16}$ The advantages of this modality are good visualization of the tumor area, with a strong fluorescent signal, less ambiguity relative to autofluorescence, as well as simpler (and sometimes cheaper) instrumentation. ${ }^{12}$ Another advantage is related to a priori knowledge of the optical properties of exogenous fluorophores; their excitation and emission spectra are well known, and their applicability is related mainly to selective localization within tissues of interest, mode of administration, and few side effects for the patients. ${ }^{10}$ On the other hand, the costs related to the process of registration and approval of such exogenous fluorophores is a significant drawback for faster introduction of such fluorescence systems in clinical practice. In many research reports both autofluorescence and exogenous fluorescence are applied simultaneously for better diagnosis of tumors, particularly in their early stages. ${ }^{13,16}$

Point measurement provides fluorescence spectral data from a single illuminated point, usually in terms of the signal intensity versus wavelength of fluorescence, while in the case of multidimensional imaging, multiple points of the tissue boundaries are illuminated in a time-sharing fashion

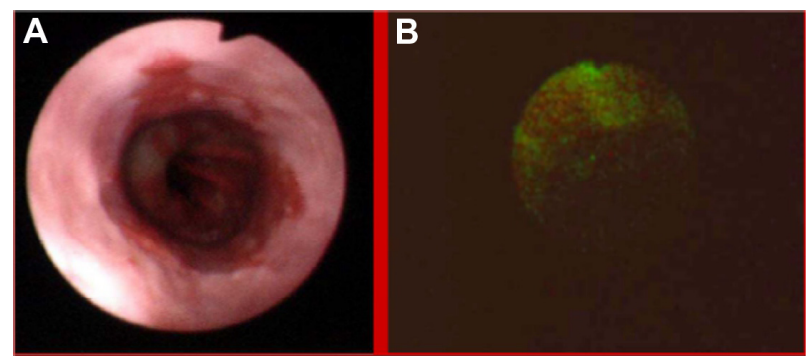

Figure I Low grade dysplasias in Barrett's esophagus in white light endoscopy (A) and autofluorescence (B) imaging.

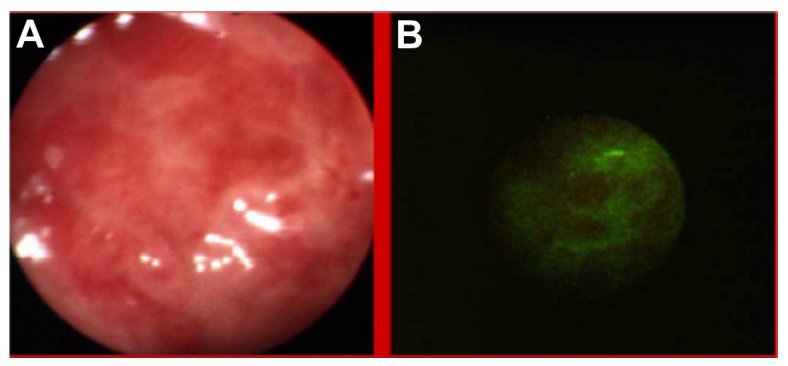

Figure 2 Ulcerative colitis in white light colonoscopy (A) and autofluorescence (B) imaging.

to form a fluorescent color map enabling determination and specification of pathological lesions. ${ }^{10,17}$

\section{Targets of fluorescence diagnosis}

In clinical practice we can distinguish five targets of fluorescence diagnosis: ${ }^{4,5}$ (1) detecting precancerous changes in order to prevent malignant transformation; (2) detecting neoplasmatic tissue in its early stages for fast removal; (3) preventing expansion, and detecting the recurrence of cancer; (4) monitoring therapy; and (5) possibly excluding neoplasmatic disease.

All present targets of fluorescence diagnosis became a part of wide oncologic prophylaxis performed at the Center for Laser Diagnostics and Therapy in Bytom. Our clinical experience has led us to use the Xillix Onco LIFE system which allows us to perform two-modal (fluorescence and optical RGB [red-green-blue] color) imaging, in real time during endoscopic procedures ${ }^{5,8}$ All images reproduced in this article were made at the Center in Bytom.

Autofluorescence imaging allowed us to detect some premalignant changes which were not visible in white light, such as low grade dysplasias in Barrett's esophagus (Figure 1), ulcerative colitis (Figure 2), high grade dysplasia in lung tissue (Figure 3), tubular adenoma (Figure 4), or lichen sclerosus (Figure 5). This early detection of neoplasmatic tissue allows us to prevent malignant transformation. ${ }^{18-21}$

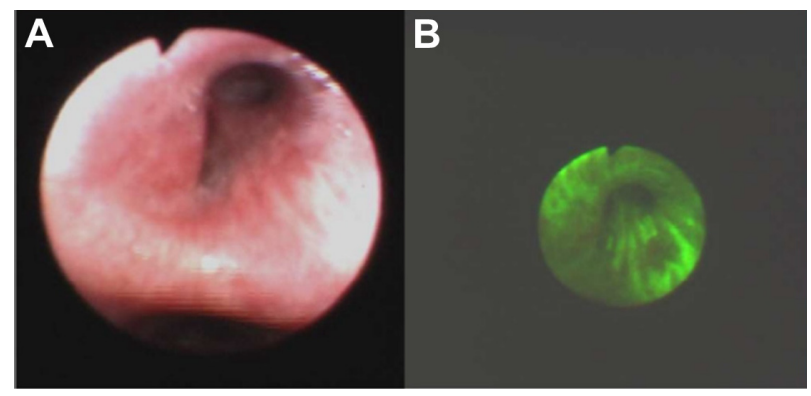

Figure 3 High grade dysplasia in lung tissue in white light bronchoscopy (A) and autofluorescence (B) imaging. 


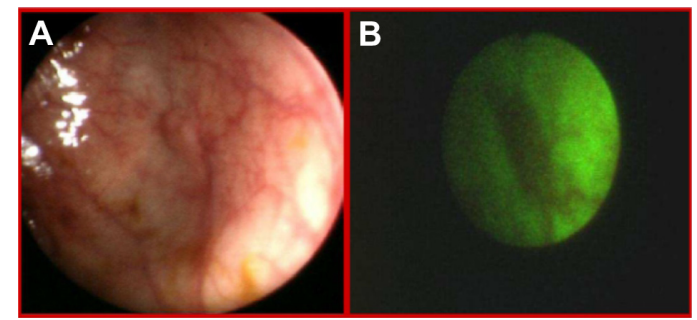

Figure 4 Tubular adenoma in white light endoscopy (A) and autofluorescence (B) imaging.

Detection of early stages of neoplasmatic tissues also enables their fast removal. Mainly in our Clinic, autofluorescence and exogenous fluorescence examination allows us to detect the early stages of precancer and cancer not only in endoscopic procedures but also on the skin and the genital organs. Histopathological examination of biopsies excised from the esophagus of a 71-year-old patient, did not detect the presence of malignant tissues, while ALA diagnosis and RGB color imaging showed the esophageal tumor (Figure 6A and B). In biopsies excised under fluorescence navigation, histopathological analysis confirmed the development of malignant changes. Similarly, in the patient with Barrett's esophagus, who 3 years ago was treated with ALA-photodynamic therapy (PDT), but who subsequently complained of dysphagia and heartburn for 4 months, malignant changes in the esophagus were localized using fluorescence and autofluorescence methods. The photodiagnosis method also allowed us to detect sunken colon cancer (Figure 7A and B) and squamous cell carcinoma in lung tissue (Figure $8 \mathrm{~A}$ and B). ${ }^{14-23}$

Autofluorescence diagnosis allows us to prevent cancer expansion and recurrence. One of its applications is estimation of radicality of polypectomy, one of the most common procedures performed in the upper and lower digestive tract. The presence of fluorescence may reveal that polypectomy is not radical, and the patient could qualify for surgery (Figure 9). Apart from this, the autofluorescence method can show the recurrence of cancer eg, in urology ${ }^{24}$ (Figure 10) or in otolaryngology (Figure 11). ${ }^{25}$

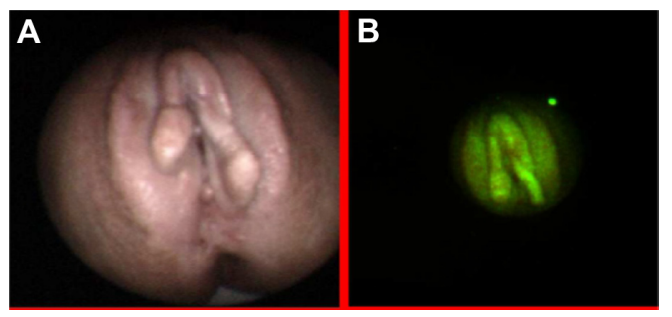

Figure 5 Lichen sclerosus in white light (A) and autofluorescence (B) imaging.

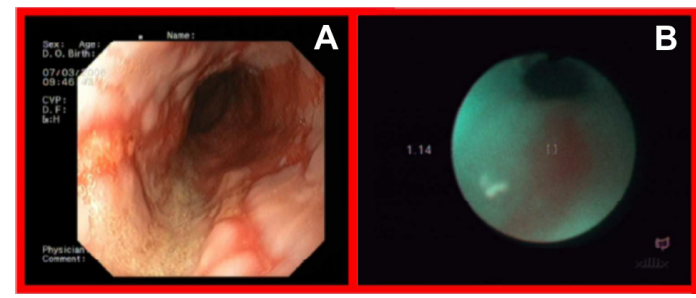

Figure 6 Esophageal tumor in white light endoscopy (A) and autofluorescence (B) imaging.

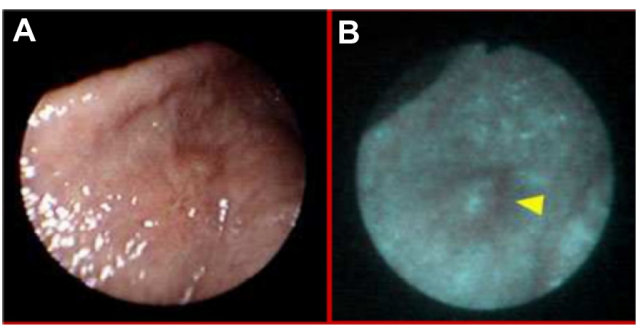

Figure 7 Sunken colon cancer in white light colonoscopy (A) and autofluorescence (B) imaging.

Note: Cancer area is marked by the arrowhead.

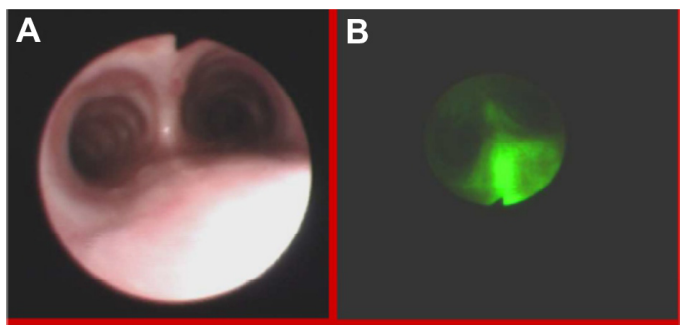

Figure 8 Lung squamous cell carcinoma in white light bronchoscopy (A) and fluorescence (B) imaging.

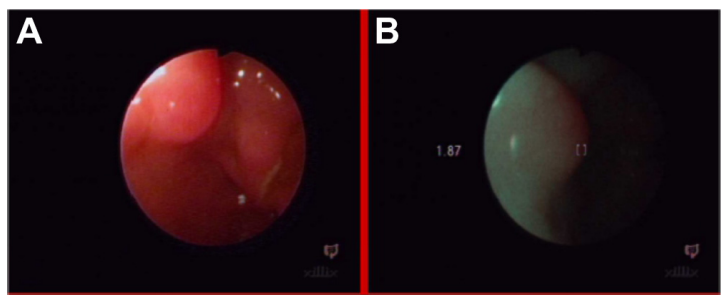

Figure 9 Estimation of radicality of polypectomy in white light (A) and autofluorescence (B) imaging.

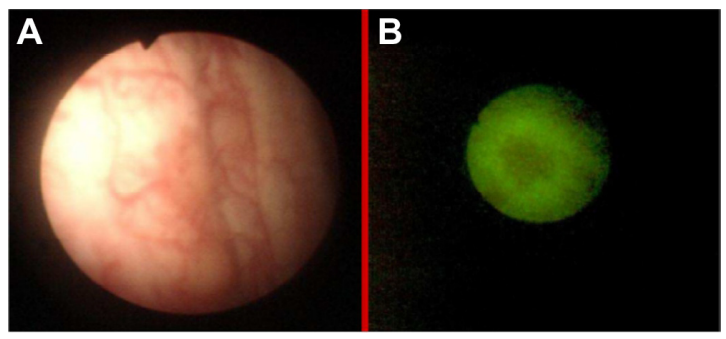

Figure 10 Recurrence of transition cell cancer in white light cystoscopy (A) and fluorescence (B) imaging. 


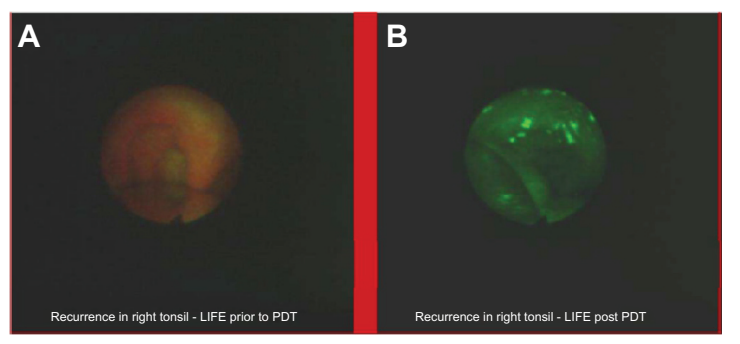

Figure I I Recurrence of squamous cell carcinoma in right tonsil before (A) and after (B) photodynamic therapy.

Abbreviations: LIFE, laser-induced fluorescence emission, PDT, photodynamic therapy.

\section{Real time autofluorescence spectroscopy}

With the use of real time autofluorescence spectroscopy, we can observe changes in the photobleaching of a photosensitizer during therapy and after. Measurements of fluorescence intensity, numerical color value, red and green color intensity, and three-dimensional imaging have allowed us to observe ALA administration in treated cancers and, allowed us to target the therapy on places with the highest fluorescence intensity after ALA administration. ${ }^{7}$ This method allows us to observe if an applied treatment is effective, or not. For example, in a patient with basal cell carcinoma, autofluorescence (Figure 12B and C) autofluorescence was effective, while in patients with acuminate condyloma in the glans, no response to the treatment was observed (Figure 13A and B). Autofluorescence diagnosis also allows for monitoring the effect of ulceration treatment with ALA-PDT (Figure 14A, B and C) and with argon laser coagulation (Figure $15 \mathrm{~A}$ and $\mathrm{B}){ }^{20}$.

\section{Autofluorescence NCV diagnosis}

Autofluorescence NCV diagnosis is an effective tool in differentiating benign and malignant lesions. ${ }^{6,8}$ The red-togreen ratio increases with the advance of histological stage, allowing us to establish the grade of malignancy, which is difficult to do, using white light endoscopy (Figure 16). We estimated that changes showing an NCV lower than 1.0 are commonly benign, but NCVs between 0.5 to 1.0 can exclude neoplasmatic disease. This method allows us to show small changes which are not visible in white light, such as polyps in the esophagus (Figure 17), glycogen acanthosis (Figure 18), or pharyngeal lipoma (Figure 19). ${ }^{8,18}$

A 71-year-old patient, who was difficult to interview, suffered from dysphagia and suspicion of esophageal tumor, without histologic confirmation in taken biopsy specimens and without dysplasia in photodynamic diagnosis (Figure 20A). The NCV method revealed a benign lesion (Figure 20B). A

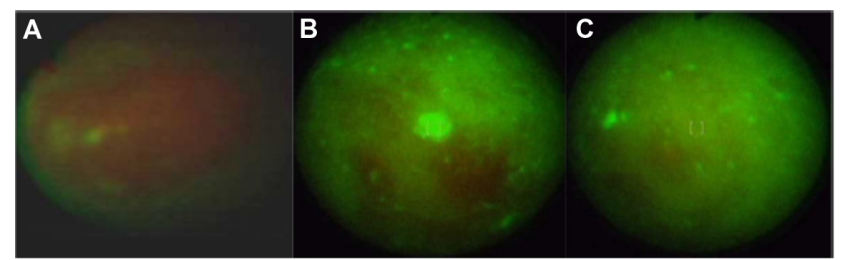

Figure 12 Monitoring of basal cell carcinoma treatment with autofluorescence method: before $(\mathbf{A})$ during $(\mathbf{B})$ and after $(\mathbf{C})$ treatment.
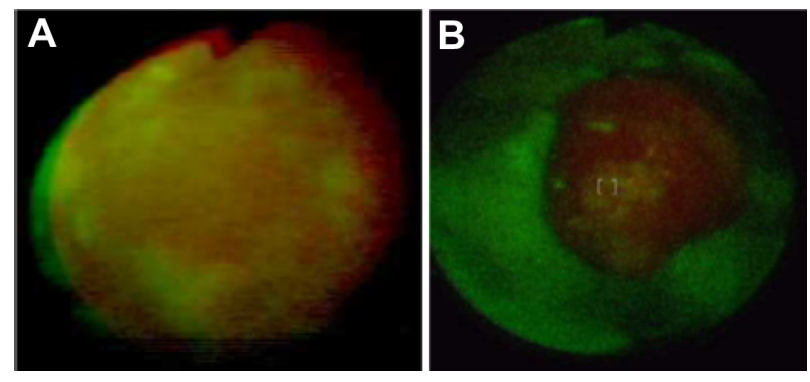

Figure 13 Monitoring of resistant to treatment acuminate condyloma in glans with autofluorescence method before (A) and during (B) treatment (until now no response).

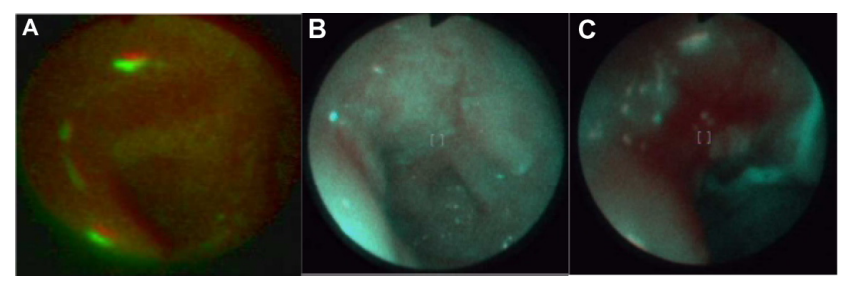

Figure 14 Monitoring the effect of ulceration treatment with photodynamic therapy: before (A), after (B), control after 3 months (C).

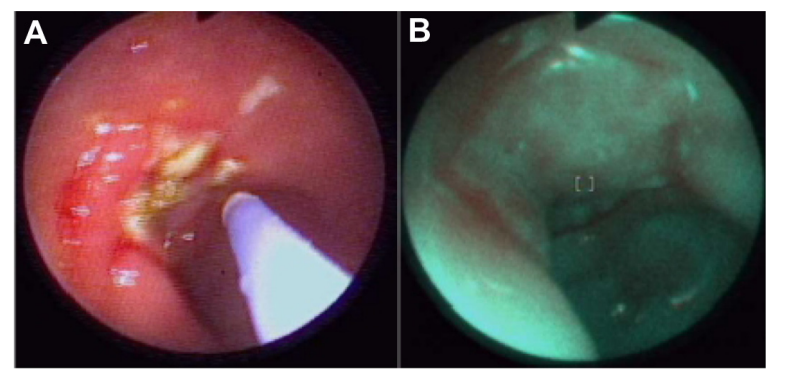

Figure I 5 Monitoring the effect of ulceration treatment with argon laser coagulation (A) with autofluorescence imaging after treatment (B).

later interview with the patient's family established a nitro solvent chemical burn about 4 years previously; thus, the observed change was probably a scar after the burn. This scar qualified for endoscopic dilatation.

These results show that fluorescence diagnosis is a fast, easy, noninvasive and sensitive diagnostic tool for estimation of treatment results in oncology. On the other hand, because 


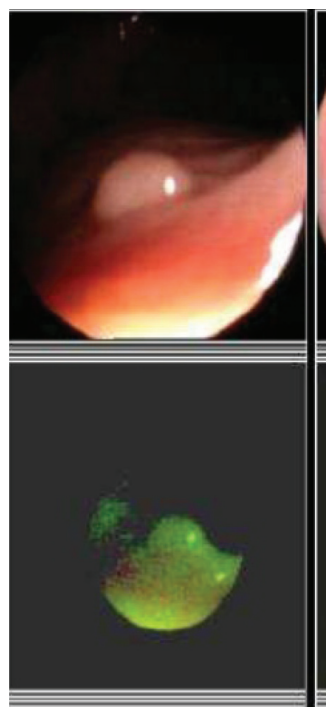

Healthy tissue

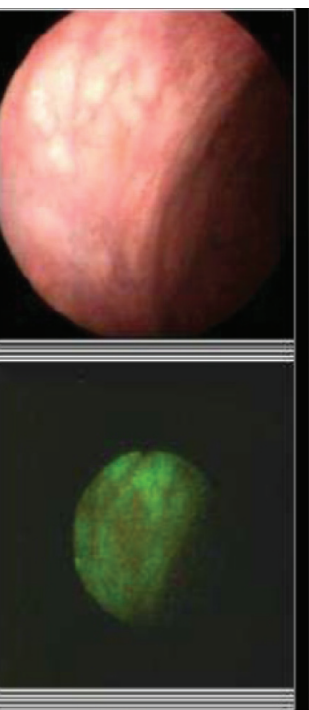

LGD

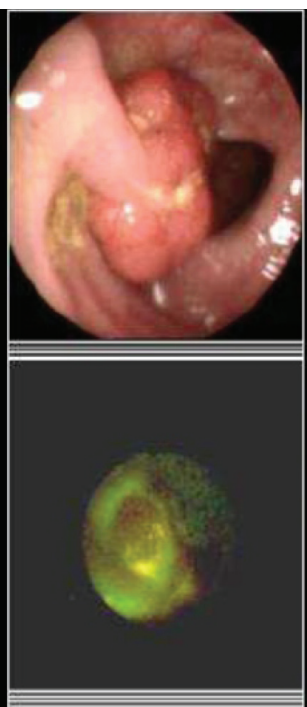

HGD

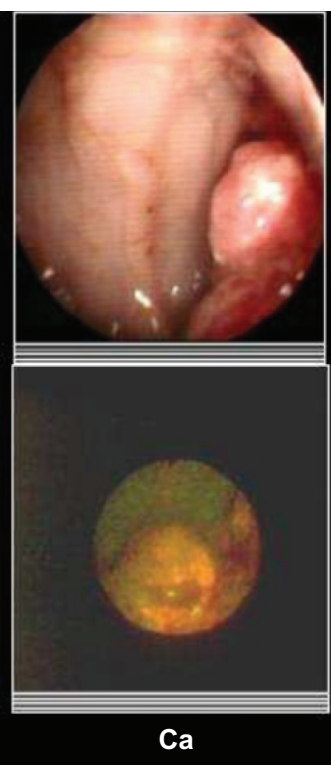

Figure I6 Differentiation of histological stages of malignancy using white light colonoscopy and fluorescence imaging. Abbreviations: Healthy tissue, polypus hyperplasticus; LGD, low grade dysplasia; HGD, high grade dysplasia; Ca, carcinoma.

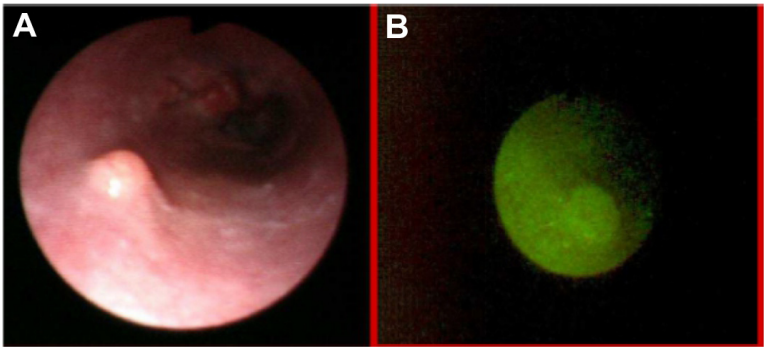

Figure 17 Polyps of esophagus, in white light endoscopy (A) and autofluorescence (B) imaging.

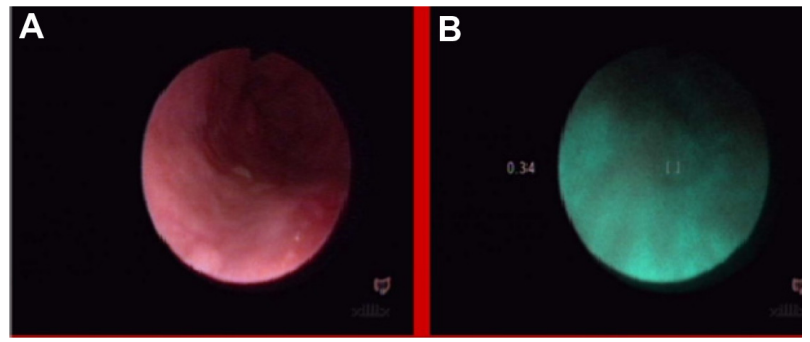

Figure 18 Glycogen acanthosis, in white light endoscopy (A) and autofluorescence (B) imaging.

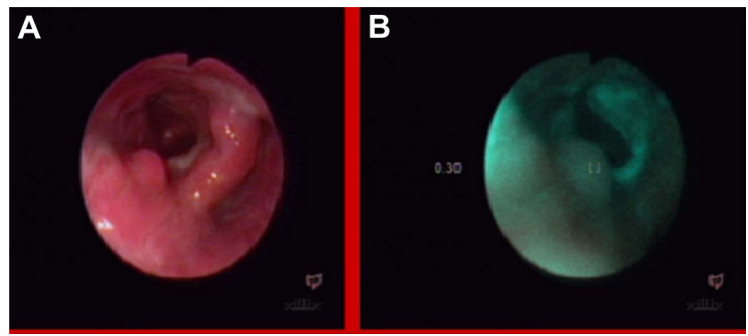

Figure 19 Pharyngeal lipoma, in white light endoscopy (A) and fluorescence (B) imaging.

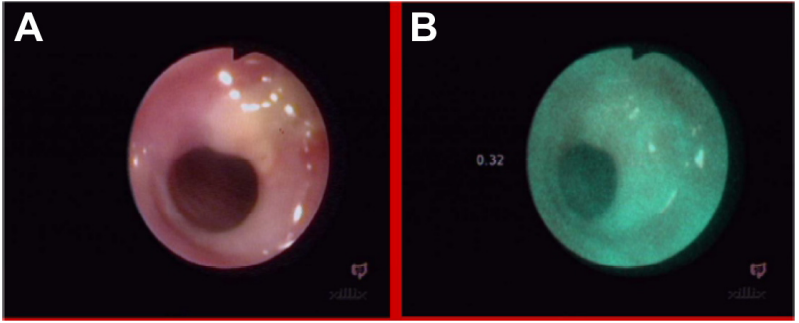

Figure 20 Esophagus of patient after nitro solvent chemical burn, in white light endoscopy (A) and autofluorescence (B) imaging.

knowledge about the usefulness of photodiagnosis is still not widespread enough in clinical practice, it is necessary to promote the advantages of this diagnostic method among clinicians.

\section{Disclosure}

The authors report no conflicts of interest in this work.

\section{References}

1. Stringer M, Moghissi K. Photodiagnosis and fluorescence imaging in clinical practice. Photodiagnosis Photodyn Ther. 2004;1:9-12.

2. Moghissi K, Stringer MR, Dixon K. Fluorescence photodiagnosis in clinical practice. Photodiagnosis Photodyn Ther. 2008;5:235-237.

3. Allison RR, Sibata CH. Photodiagnosis for cutaneous malignancy: a brief clinical and technical review. Photodiagnosis Photodyn Ther. 2008;5:247-250.

4. Mitton D, Ackroyd R. A brief overview of photodynamic therapy in Europe. Photodiagnosis Photodyn Ther. 2008;5:103-111.

5. Sieron A, Kwiatek S. Twenty years of experience with PDD and PDT in Poland - Review. Photodiagnosis Photodyn Ther. 2009;6:73-79.

6. de Veld DCG, Skurichina M, Witjes MJH, Duin RPW, Sterenborg HJCM, Roodenburg JLN. Clinical study for classification of benign, dysplastic, and malignant oral lesions using autofluorescence spectroscopy. J Biomed Opt. 2004;9:940-950. 
7. Sieroń A, Gibiński P, Pustelny T, et al. Optical biopsy using spectral camera in BCC and oral leukoplakia. Photodiagnosis Photodyn Ther. 2008;5:271-275.

8. Sieroń-Stołtny K, Kwiatek S, Latos W, et al. Autofluorescence endoscopy with "real-time" digital image processing in differential diagnostics of selected benign and malignant lesions in the oesophagus. Photodiagnosis Photodyn Ther. 2012;9:5-10.

9. Wagnières GA, Star WM, Wilson BC. In vivo fluorescence spectroscopy and imaging for oncological applications. Photochem Photobiol. 1998;68:603-632.

10. Borisova E, Vladimirov B, Ivanova R, Avramov L. Light-Induced fluorescence techniques for gastrointestinal tumour detection. In: Pascu O, editor. New Techniques in Gastrointestinal Endoscopy. Shanghai: InTech-Rijeka; 2011:231-252.

11. Filip M, Iordache S, Săftoiu A, Ciurea T. Autofluorescence imaging and magnification endoscopy. World J Gastroenterol. 2011;17:9-14.

12. Roberts-Thomson IC, Singh R, Teo E, Nguyen NQ, Lidums I. The future of endoscopy. J Gastroenterol Hepatol. 2010;25:1051-1057.

13. Ell C. Improving endoscopic resolution and sampling: fluorescence techniques. Gut. 2003;52(Suppl IV):30-33.

14. Osada T, Arakawa A, Sakamoto N, et al. Autofluorescence imaging endoscopy for identification and assessment of inflammatory ulcerative colitis. World J Gastroenterol. 2011;17:5110-5116.

15. Yoshida T, Inoue H, Usui S, Satodate H, Fukami N, Kudo S-E. Narrowband imaging system with magnifying endoscopy for superficial esophageal lesions. Gastrointest Endoscopy. 2004;59:288-295.

16. Da Costa RS, Wilson BC, Marcon NE. Fluorescence and spectral imaging. Scientific WorldJournal. 2007;7:2046-2071.

17. Ntziachristos V, Ripoll J, Wang LV, Weissleder R. Looking and listening to light: the evolution of whole-body photonic imaging. Nature Biotechnol. 2005;23:313-320.
18. Niepsuj K, Niepsuj G, Cebula W, et al. Autofluorescence endoscopy for detection of high-grade dysplasia in short-segment Barrett's esophagus. Gastrointest Endoscopy. 2003;58:715-719.

19. Biniszkiewicz T, Olejek A, Kozak-Darmas I, Sieroń A. Therapeutic effects of 5-ALA-induced photodynamic therapy in vulvar lichen sclerosus. Photodiagn Photodyn Ther. 2005;2:157-160.

20. Latos W, Kawczyk-Krupka A, Ledwoń A, et al. The role of autofluorescence colonoscopy in diagnosis and management of solitary rectal ulcer syndrome. In: Proceedings of the SPIE. 6859, Imaging, Manipulation, and Analysis of Biomolecules, Cells, and Tissues VI. Article 685906, March 3, 2008; doi:10.1117/12.762314

21. Sieroń A, Adamek M, Kawczyk-Krupka A, Mazur S, Ilewicz L. Photodynamic therapy (PDT) using topically applied $\delta$-aminolevulinic acid (ALA) for the treatment of oral leukoplakia. J Oral Pathol Med. 2003;32:330-336.

22. De Veld DCG, Witjes MJH, Sterenborg HJCM, Roodenburg JLN. The status of in vivo autofluorescence spectroscopy and imaging for oral oncology. Oral Oncology. 2005;41:117-131.

23. Moghissi K, Dixon K, Stringer MR. Current indications and future perspective of fluorescence bronchoscopy: a review study. Photodiagnosis Photodyn Ther. 2008;5:238-246.

24. Szygula M, Wojciechowski B, Adamek M, et al. Fluorescent diagnosis of urinary bladder cancer - a comparison of two diagnostic modalities. Photodiagnosis Photodyn Ther. 2004;1:23-26.

25. Betz CS, Mehlmann M, Rick K, et al. Autofluorescence imaging and spectroscopy of normal and malignant mucosa in patients with head and neck cancer. Lasers Surg Med. 1999;25:323-334.
OncoTargets and Therapy

\section{Publish your work in this journal}

OncoTargets and Therapy is an international, peer-reviewed, open access journal focusing on the pathological basis of all cancers, potential targets for therapy and treatment protocols employed to improve the management of cancer patients. The journal also focuses on the impact of management programs and new therapeutic agents and protocols on

\section{Dovepress}

patient perspectives such as quality of life, adherence and satisfaction The manuscript management system is completely online and includes a very quick and fair peer-review system, which is all easy to use. Visit http://www.dovepress.com/testimonials.php to read real quotes from published authors. 